\title{
A method for the direct measurement of surface tension of collected atmospherically relevant aerosol particles using atomic force microscopy
}

\author{
Andrew D. Hritz ${ }^{1}$, Timothy M. Raymond ${ }^{1}$, and Dabrina D. Dutcher ${ }^{1,2}$ \\ ${ }^{1}$ Department of Chemical Engineering, Bucknell University, Lewisburg, Pennsylvania 17837, USA \\ ${ }^{2}$ Department of Chemistry, Bucknell University, Lewisburg, Pennsylvania 17837, USA
}

Correspondence to: Dabrina D. Dutcher (dabrina.dutcher@bucknell.edu)

Received: 14 January 2016 - Published in Atmos. Chem. Phys. Discuss.: 19 January 2016

Revised: 2 June 2016 - Accepted: 20 June 2016 - Published: 3 August 2016

\begin{abstract}
Accurate estimates of particle surface tension are required for models concerning atmospheric aerosol nucleation and activation. However, it is difficult to collect the volumes of atmospheric aerosol required by typical instruments that measure surface tension, such as goniometers or Wilhelmy plates. In this work, a method that measures, ex situ, the surface tension of collected liquid nanoparticles using atomic force microscopy is presented. A film of particles is collected via impaction and is probed using nanoneedle tips with the atomic force microscope. This micro-Wilhelmy method allows for direct measurements of the surface tension of small amounts of sample.

This method was verified using liquids, whose surface tensions were known. Particles of ozone oxidized $\alpha$-pinene, a well-characterized system, were then produced, collected, and analyzed using this method to demonstrate its applicability for liquid aerosol samples. It was determined that oxidized $\alpha$-pinene particles formed in dry conditions have a surface tension similar to that of pure $\alpha$-pinene, and oxidized $\alpha$-pinene particles formed in more humid conditions have a surface tension that is significantly higher.
\end{abstract}

\section{Introduction}

According to the Fifth Assessment Report of the Intergovernmental Panel on Climate Change, clouds and aerosols contribute the largest uncertainty to understanding changes in climate (Boucher et al., 2013). Aerosols affect the climate directly by reflecting or absorbing solar radiation, and indirectly when they form cloud particles (Boucher et al., 2013). A major difficulty in modeling particle nucleation and aerosol activation lies in determining physical properties of particles on the nanoscale without precise knowledge about chemical composition.

Recent studies in particle nucleation and cloud droplet activation have used various methods to estimate particle surface tension, which is a very important parameter in modeling both processes (Duplissy et al., 2008; Kiss et al., 2005; Laaksonen and McGraw, 1996; Moldanova and Ljungström, 2000; Petters et al., 2009; Prisle et al., 2010; Sorjamaa et al., 2004; Wex et al., 2009). Particle nucleation is described by the Kelvin equation (Laaksonen and McGraw, 1996), which requires knowledge about surface tension of the nucleating particle (Laaksonen and McGraw, 1996; Schmelzer et al., 1996). Not surprisingly, direct measurement of the surface tension of particles near activation state conditions has not been possible. Studies on nucleation often rely on an assumption about the composition and use compiled values for bulk surface tension including values extrapolated from other phases, estimated or interpolated from similar compounds or simply assume "physically reasonable values" (Daisey and Hopke, 1993; Moldanova and Ljungström, 2000). Hansen et al. (2015), demonstrated the magnitude of the error that can occur when commonly made assumptions about surface tensions are used in models. A direct method of measuring the surface tensions of particles immediately after nucleation is preferable to these assumptions and would likely reduce the error in particle nucleation models. 


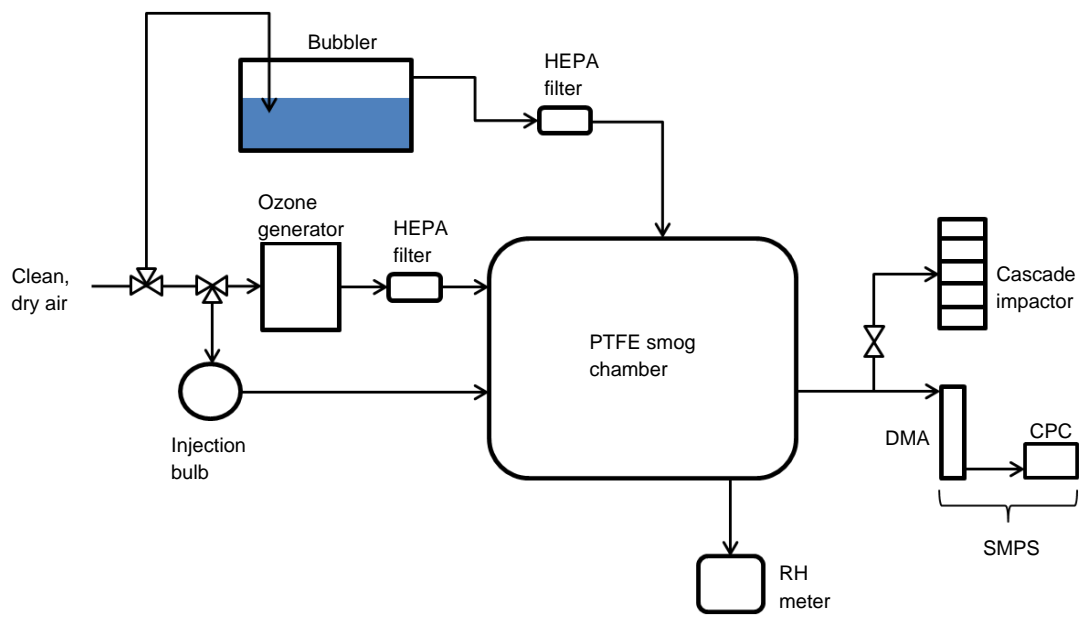

Figure 1. Experimental setup used to generate and collect oxidized $\alpha$-pinene particles. The smog chamber is initially flushed with dry or wet air. Once the relative humidity in the chamber is established, particles are generated in the smog chamber by mixing $\alpha$-pinene and ozone. Resulting particles are either analyzed with the SMPS or sampled using the cascade impactor.

Köhler theory is used to predict the properties of activating cloud condensation nuclei (Köhler, 1936). The Köhler equation balances the Kelvin effect with Raoult's Law in order to describe particle activation. The Kohler equation applies equilibrium thermodynamics to describe the process in which water vapor condenses to form liquid droplets.

$\ln \left(\frac{p_{\mathrm{w}}\left(D_{p}\right)}{p^{0}}\right)=\frac{4 M_{\mathrm{w}} \sigma_{\mathrm{w}}}{R T \rho_{\mathrm{w}} D_{p}}-\frac{6 n_{\mathrm{s}} M_{\mathrm{w}}}{\pi \rho_{\mathrm{w}} D_{p}^{3}}$,

where $T$ is absolute temperature, $R$ ideal gas constant, $p_{\mathrm{w}}$ droplet water vapor pressure, $p_{0}$ saturation vapor pressure over a flat surface, $\sigma_{\mathrm{w}}$ droplet surface tension, $\rho_{\mathrm{w}}$ density of pure water, $n_{\mathrm{s}}$ moles of solute, $M_{\mathrm{w}}$ molecular weight of water, and $D_{\mathrm{p}}$ droplet diameter (Köhler, 1936). Thus, similar problems arise in specifying physical properties used in the Kelvin term of the Köhler equation. To date, there has been little consistency between assumptions used for the activated particles' surface tensions. Many researchers (Conant et al., 2002; Huff Hartz et al., 2005; Petters and Kreidenweis, 2007; Prenni et al., 2007) have assumed that, at activation, the particles consist mainly of water, so a surface tension of pure water was used. Though this is a reasonable initial assumption, it neglects the depressive effect of organic surfactants on the activating particles' surface tensions (Facchini et al., 1999; Kiss et al., 2005). It is now generally agreed upon that, for most activating particles with these surfactants, the surface tension is reduced by about 10$15 \%$ (Asa-Awuku et al., 2010; Engelhart et al., 2008; Facchini et al., 2000; King et al., 2009). Several methods have been used to predict this surface tension reduction. Some researchers have collected particles and diluted them so as to allow for a direct measurement using conventional instruments (Asa-Awuku et al., 2008; Henning et al., 2005; Moore et al., 2008; Schwier et al., 2013). These values were then ex- trapolated back to the initial concentration by fitting them to a Szyskowski-Langmuir isotherm. Occasionally, surface tensions for the particles have been back-calculated using Köhler theory analysis when all other parameters are known or estimated (Asa-Awuku et al., 2010; Engelhart et al., 2008). Others (Kiss et al., 2005; Raymond and Pandis, 2002) have prepared solutions mimicking the bulk chemical composition of aerosol particles and directly measured their surface tensions. However, none of these methods directly measures the surface tension of the actual particles in question.

Yazdanpanah (Yazdanpanah et al., 2008) has developed a method to measure the surface tension of small $(\sim 200 \mathrm{~nm}$ in diameter) droplets and films using constant-diameter nanoneedle tips on the atomic force microscope. In this work, we will show how his method has been adapted to accurately measure the surface tensions of collected atmospheric aerosols.

\section{Experimental methods}

\subsection{Particle generation}

In this project, oxidized $\alpha$-pinene particles were generated in a $1 \mathrm{~m}^{3}$ polytetrafluoroethylene (PTFE) smog chamber (Fig. 1). Particles were formed in either "dry" $(<10 \% \mathrm{RH})$ or "wet" $(67 \% \mathrm{RH})$ conditions. To generate the "dry" conditions, the chamber was flushed with clean, dry air for several hours. Compressed air was cleaned using a TSI 3074B filtered air supply. To generate the "wet" conditions, clean air was bubbled through water at 2 liters per minute $\left(\mathrm{L} \mathrm{min}^{-1}\right)$, filtered, and sent to the smog chamber. The chamber was flushed with this humid airstream until a maximum relative humidity was reached. Relative humidity was measured using a Vaisala HM337 Humidity and Temperature Transmit- 

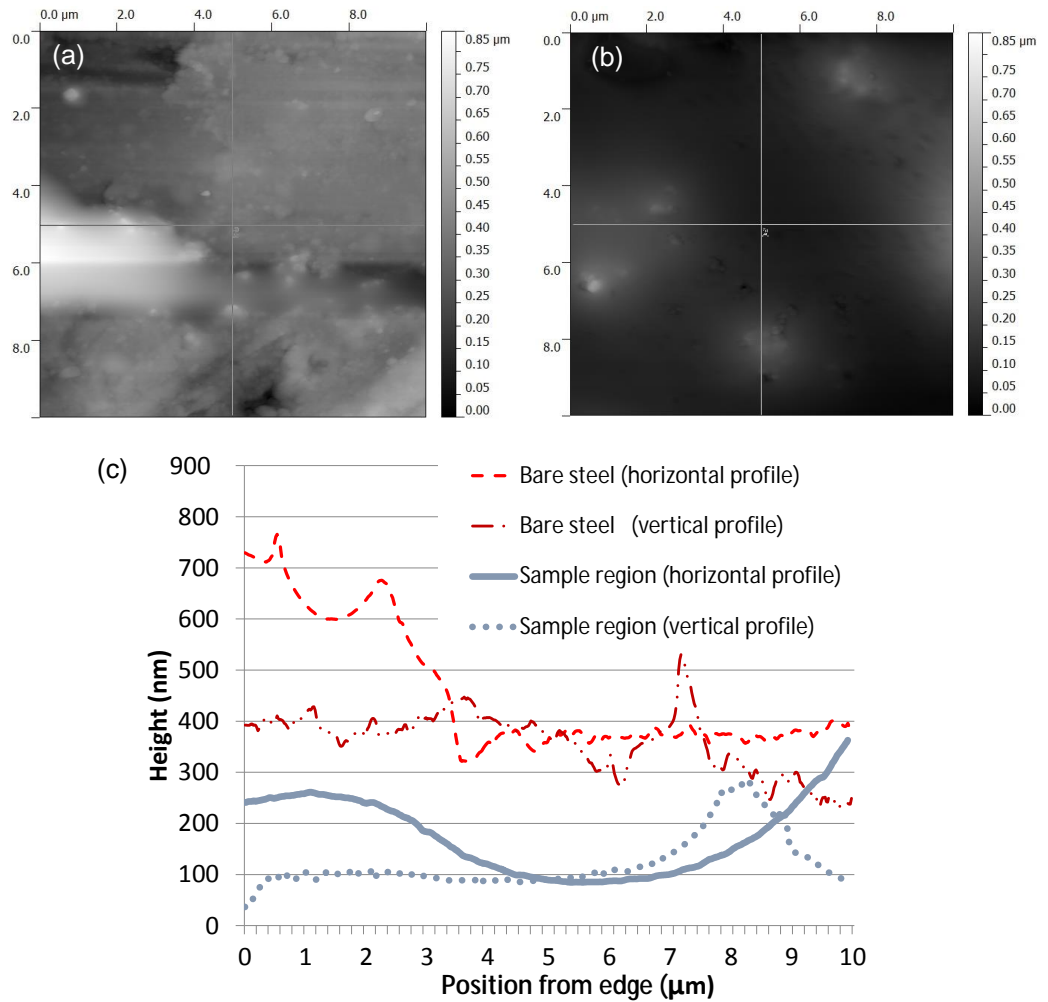

Figure 2. Panel (a) shows an AFM surface scan of cleaned (no sample) puck. The surface is rough at this microscopic level. Panel (b) shows an AFM scan of the same puck after sampling. This image was collected in the sample deposit region. It shows that the roughness gets filled in by the sample. Panel (c) shows the centered vertical and horizontal traces from these analyses. Significant roughness is observed on the steel that is not observed on the collected sample. This indicates that the sample could flow; i.e., it had liquid characteristics at the time of sampling.

ter. Neither the water content of the particles nor the surface tensions of the particles generated under dry and wet conditions are likely to be directly proportional to the relative humidities (Jonsson et al., 2007).

During experiments, the dry, cleaned airstream was sent into the smog chamber at $2 \mathrm{~L} \mathrm{~min}^{-1}$. This airstream could be diverted either through a sample port or through an ozone generator (Poseidon Ozone Generator by Ozotech) in series with a High-Efficiency Particulate Air (HEPA) filter before entering the chamber. An outlet port from the chamber could be connected either to a scanning mobility particle sizer (a 3080 TSI differential mobility analyzer in series with the 3775 TSI condensation particle counter) or a cascade impactor (I-1L Cascade impactor by PIXE). Experiments were only conducted when the initial particle concentration in the smog chamber was below 100 particles $\mathrm{cm}^{-3}$, as measured by the scanning mobility particle sizer (SMPS).

At the start of each experiment, ozone was added to the smog chamber. If particle counts in the smog chamber remained low after about $5 \mathrm{~min}$, indicating a chamber free of oxidizable volatile organic compounds, $5 \mu \mathrm{L}$ of liquid $\alpha$ pinene (97\% pure, Acros Organics) would be then injected into a sample port, where it would be vaporized and carried into the smog chamber. Ozone and $\alpha$-pinene were added in a roughly 1:1 molar ratio; the high starting concentrations were necessary so that an adequate particle volume would form for collection later. The resulting oxidized $\alpha$-pinene particles were allowed to age in the chamber for $90 \mathrm{~min}$. The ozone- $\alpha$-pinene system was selected because it is one of the more, if not the most, characterized secondary organic aerosol (SOA) systems. Speciation and chemical characterization results from similar systems have been reported by various researchers (e.g., Jang and Kamens, 1999; Praplan et al., 2015; Tu et al., 2016; Yu et al., 1999).

During the aging process, particle size distribution data were collected with the SMPS. The SMPS sample flow rate was $0.3 \mathrm{~L} \mathrm{~min}^{-1}$ and the sheath flow rate used on the differential mobility analyzer (DMA) was $3 \mathrm{~L} \mathrm{~min}^{-1}$. These settings allowed for collection of particle size distribution data over the range of 15 to $660 \mathrm{~nm}$. The low sampling flow rate ensured that the smog chamber operated under positive pressure. The size of the oxidized $\alpha$-pinene particles followed a log-normal distribution, whose center shifted to larger sizes over time. In the period where particles aged, the modal diameter increased from around 120 to $200 \mathrm{~nm}$. The most significant changes in particle size distribution occurred in 
Table 1. Surface tension of bulk liquids used for standardization, measured by the Wilhelmy plate at $23.9^{\circ} \mathrm{C}$. Averages reported as "average \pm standard error $(s / \sqrt{n})$ ". Pure oleic acid has a surface tension of $32.79 \mathrm{dyn} \mathrm{cm}^{-2}$ at $20^{\circ} \mathrm{C}$ (Chumpitaz et al., 1999), and pure $\alpha$-pinene has a surface tension of $26.0 \mathrm{dyn} \mathrm{cm}^{-1}$ at $25^{\circ} \mathrm{C}$ (Daisey and Hopkey, 1993). Measured values on Wilhelmy plate are close to reported values, considering differences in purity and temperature.

\begin{tabular}{lr}
\hline Component & Surface tension $\left(\mathrm{dyn}^{-1}\right)$ \\
\hline Oleic acid & 29.47 \\
$(90 \%$ purity $)$ & 29.53 \\
\hline Average & $29.50 \pm 0.03$ \\
\hline$\alpha$-pinene & 25.75 \\
$(97 \%$ purity $)$ & 25.36 \\
\hline Average & $25.6 \pm 0.2$ \\
\hline
\end{tabular}

the first hour after the $\alpha$-pinene was introduced to the smog chamber. The 90 min aging period ensured minimal changes in particle size distribution during collection. A schematic of the experimental setup is shown in Fig. 1.

\subsection{Particle collection}

At 90 min after $\alpha$-pinene was introduced to the smog chamber, the outlet of the chamber was switched to feed to the cascade impactor. The second smallest stage (L2) was used to collect the particles on a cleaned steel disk. The $50 \%$ aerodynamic cutoff diameter for this stage at $4 \mathrm{~L} \mathrm{~min}^{-1}$ was $40 \mathrm{~nm}$. After $90 \mathrm{~min}$ a visible particle film had collected on the disk. The particles deposit in a circular region $\sim 6 \mathrm{~mm}$ in diameter on the steel disc. The steel disc before and after sample collection was imaged using a ScanAsyst and PeakForce Tapping-mode atomic force microscope (AFM) microscope. These images are displayed in Fig. 2a and b. These images show that the steel disk is rough. After sampling the surface is smoother indicating that the sample flowed and filled in the roughness. Two traces, centered vertically and horizontally, from each image are shown in Fig. 2c.

\subsection{Sample analysis}

A Veeco Multimode V AFM and NaugaNeedle NN-HARFM60 probes were used to analyze the particle film collected on the disk. The probes consist of a flat, flexible cantilever, and a nanoneedle mounted normally to the cantilever at its end. The Ga-Ag nanoneedles are shaped as cylinders on the order of $100 \mathrm{~nm}$ in diameter and $10 \mu \mathrm{m}$ in length. A microWilhelmy method developed by Yazdanpanah et al. (2008), described below, was then used to measure the surface tension of the samples.

The sample was analyzed with the AFM in force mode. In this mode, the AFM's piezoelectric transducers push the

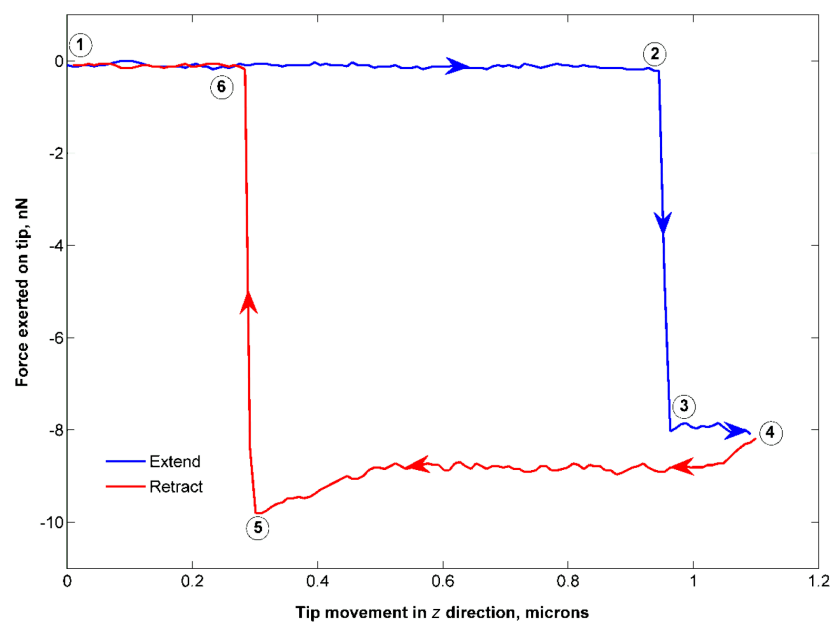

Figure 3. A typical force curve obtained using NaugaNeedle NNHAR-FM60 probes and an atomic force microscope. The blue line indicates the probe approaching the sample, and the red line indicates the probe retracting from the sample. At point 1, the nanoneedle is approximately $1 \mu \mathrm{m}$ from the surface of the liquid sample. At point 2, the nanoneedle is just above the surface of the liquid. At point 3, the nanoneedle has touched the liquid, which wicks up and exerts a downward force on the probe. At point 4 , the nanoneedle begins to pull out of the liquid. At point 5 , the liquid is just about to break from the end of the nanoneedle, and the contact angle of the liquid-needle interface approaches zero. At point 6 , the nanoneedle has been pulled out of the liquid sample. The probe retracts back to point 1.

sample film up to and away from the probe with high precision. The downward force exerted on the probe was recorded by the AFM as a function of its location relative to the film's surface. A force curve obtained with the AFM is presented in Fig. 3.

In Fig. 3, the curve in blue illustrates the force exerted on the probe as it approaches and touches the sample surface. The curve in red illustrates the force exerted on the probe as it is pulled from the sample. If it is assumed that only forces related to the surface tension of the liquid film are exerted on the probe, then Eq. (2) will be

$F_{\text {probe }}=\sigma \cdot L \cdot \cos (\theta)$,

where $\sigma$ is the surface tension of the sample, $L$ is the wetted perimeter of the tip, and $\theta$ is the contact angle between the fluid and the tip. For a more complete derivation of this equation see Yum and Yu (2006).

Because the nanoneedle has a cylindrical geometry, the wetted perimeter, $L$, is constant during all force measurements. This can be seen by the near-constant negative force exerted on the probe when it is initially retracting out of the sample. The increase in the downward force before the nanoneedle is completely pulled from the sample is attributed to a decrease in the contact angle. At the point the sample breaks away from the nanoneedle, the contact angle is zero. 
Table 2. Measured and calculated values obtained during three experiments. In the first experiment, $\alpha$-pinene was used as the standard, oleic acid was used as a check standard, and the oxidized $\alpha$-pinene particles were generated in dry conditions. In the second experiment, oleic acid was used as the standard, there was no check standard, and the oxidized $\alpha$-pinene particles were generated in dry conditions. In the third experiment, $\alpha$-pinene was used as the standard, there was no check standard, and the oxidized $\alpha$-pinene particles were generated in wet conditions.

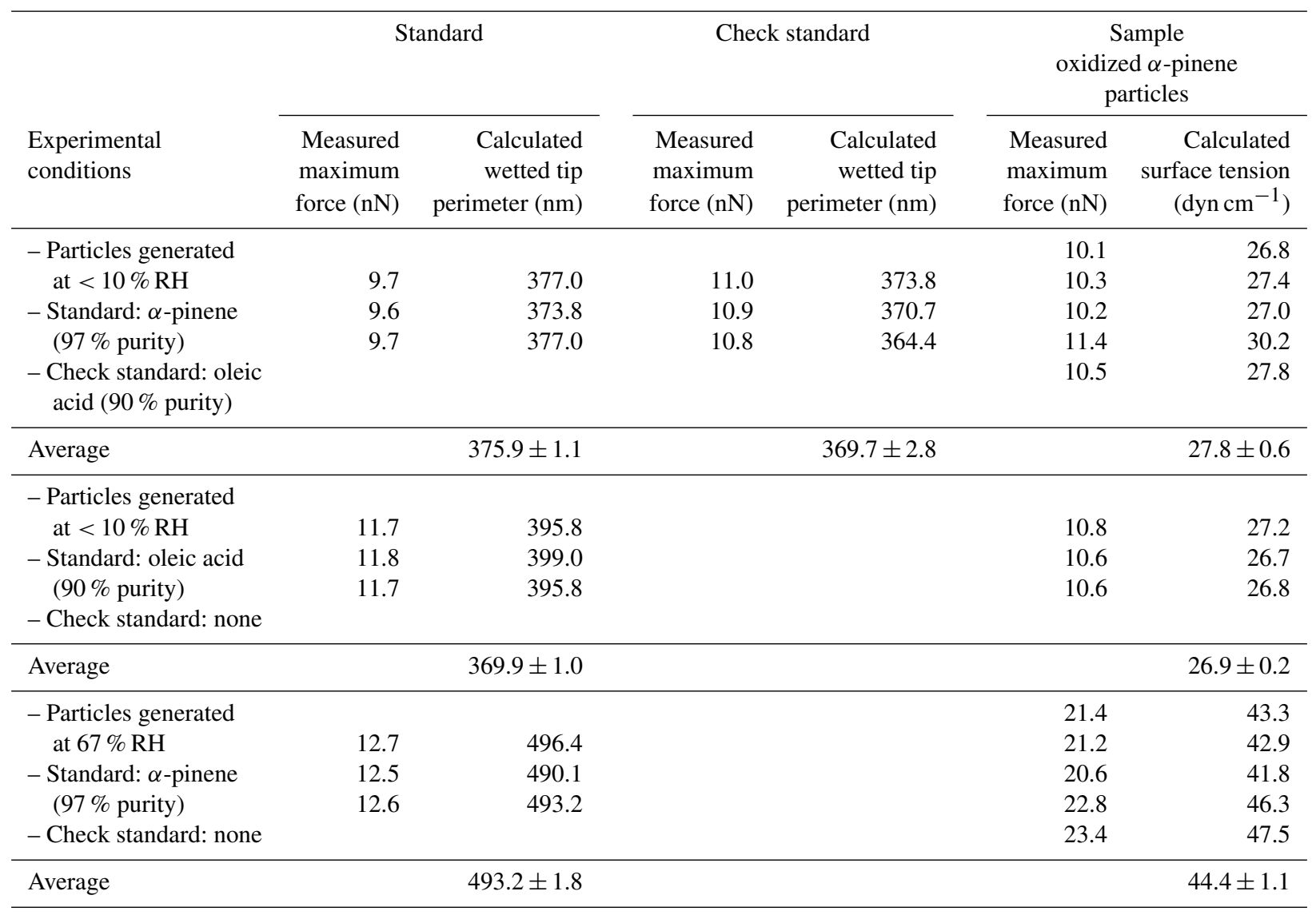

When this angle is zero and the needle is smaller than the capillary length (Uddin et al., 2011), Eq. (2) is as follows:

$\sigma=\frac{F_{\text {probe }}}{L}$

For this project, Eq. (3) (Padday et al., 1975) was used, using the force reading at the point the nanoneedle broke from the sample. This corresponds to point 5 in Fig. 3. The magnitude of the force at the break-away step suggests that the collected sample is liquid rather than a glassy or amorphous solid observed for some oxidized volatile organic compound (VOC) systems.

Several aspects of the AFM system were calibrated daily before the collected $\alpha$-pinene particles were analyzed, typically during particle collection. Because the AFM directly measures the deflection of the cantilever, a force exerted on the nanoneedle could only be obtained after calibrating the cantilever's deflection and determining its spring constant. In the AFM, a laser is reflected off of the cantilever into a photodetector; cantilever deflection is measured by the movement of the laser on the photodetector. To calibrate this mea- surement, the probe was gently pushed into a hard, steel surface. The slope of the force curve when the probe is in contact with the surface indicates the observed cantilever deflection from the photodetector ( $y$ axis of the force curve) versus the actual distance the surface is moving the cantilever ( $x$ axis of the force curve). This slope was entered into the AFM's operating program.

The spring constant of the tip was found using a thermal tune. The thermal tune is a common method to calculate the spring constant using measurements of the cantilever's response to thermal noise (Serry, 2005). The native Veeco software was used to perform the thermal tune. After these calibrations, the AFM will produce force curves that relate force and distance accurately.

In order to calculate surface tension from force data, the wetted perimeter of the nanoneedle also had to be obtained. This was done by obtaining force curves of liquid standards and using Eq. (3) to back-calculate the wetted perimeter given force and surface tension information. Two liquid standards were used: $90 \%$ pure oleic acid (Sigma-Aldrich) and 
Table 3. Measured and approximated surface tensions of $\alpha$-pinene particles. Bulk $\alpha$-pinene and dry, oxidized $\alpha$-pinene particles have a similar surface tension. Wet $\alpha$-pinene particles have a higher surface tension. Measurements from this study are shown in italicized font, other values are given for context.

\begin{tabular}{lrl}
\hline RH at particle creation $(\%)$ & Surface tension $\left(\mathrm{dyn}^{-1}\right)$ & Description, source \\
\hline $\mathrm{n} / \mathrm{a}$ & 25.6 & $\begin{array}{l}\text { Pure } \alpha \text {-pinene, bulk } \\
\text { This experiment; } \text { Wilhelmy plate }\end{array}$ \\
\hline$<10$ & 27.5 & $\begin{array}{l}\text { Oxidized } \alpha \text {-pinene particles } \\
\text { This experiment; } \text { AFM measurements }\end{array}$ \\
\hline 67 & 44.4 & $\begin{array}{l}\text { Oxidized } \alpha \text {-pinene particles } \\
\text { This experiment; } \text { AFM measurements }\end{array}$ \\
\hline$>100$ & & $\begin{array}{l}\text { Oxidized } \alpha \text {-pinene particles, assume depressed } \\
\text { surface tension of pure water } \\
(\text { activation })\end{array}$ \\
& 61.7 & Engelhart et al. (2008) \\
\hline$>100$ & 72.5 & $\begin{array}{l}\text { Oxidized } \alpha \text {-pinene particles, assume surface } \\
\text { tension of pure water }\end{array}$ \\
(activation) & & Huff Hartz et al. (2005); Prenni et al. (2007) \\
\hline
\end{tabular}

$97 \%$ pure, non-oxidized liquid $\alpha$-pinene. The surface tensions of these two standards were measured using a Wilhelmy plate (Sigma 703D, KSV Instruments Ltd.); results are shown in Table 1. Measurements for the standards yielded lower values compared to the literature for pure oleic acid and $\alpha$-pinene. Because the standards were not completely pure, this was not unexpected, and surface tension values obtained from the Wilhelmy plate were used.

A summary of the steps used to calibrate and analyze samples on the AFM is shown in Fig. 4.

\section{Results and discussion}

Surface tension data were obtained for oxidized $\alpha$-pinene particles. The AFM's measurements and calculated values are presented in Table 2. Both "dry" oxidized $\alpha$-pinene particles and "wet" oxidized $\alpha$-pinene particles were analyzed. The mean surface tension of "dry" oxidized $\alpha$-pinene particles was found to be $27.5 \mathrm{dyn} \mathrm{cm}^{-1}$ at $23^{\circ} \mathrm{C}$, with an average uncertainty of $1.1 \mathrm{dyn} \mathrm{cm}^{-1}$. This is similar to the surface tension of pure $\alpha$-pinene as reported in the literature (Daisey and Hopke, 1993) and measured with our Wilhelmy plate. The mean surface tension of "wet" oxidized $\alpha$-pinene particles was found to be $44.4 \mathrm{dyn} \mathrm{cm}^{-1}$ at $23^{\circ} \mathrm{C}$, with an uncertainty of $2.4 \mathrm{dyn}^{-1}$.

The results presented in Table 2 include a set of standards, which were done for every set of measurements. The purpose of this standard was to allow for the determination of the perimeter of the nanoneedle. For the first set of reported measurements, a check standard was also added to verify that the perimeter measurement was correct. This check standard is not required for each set of measurements. The surface tensions measured here were compared to the surface tensions of the standards measured and presented in Table 1.

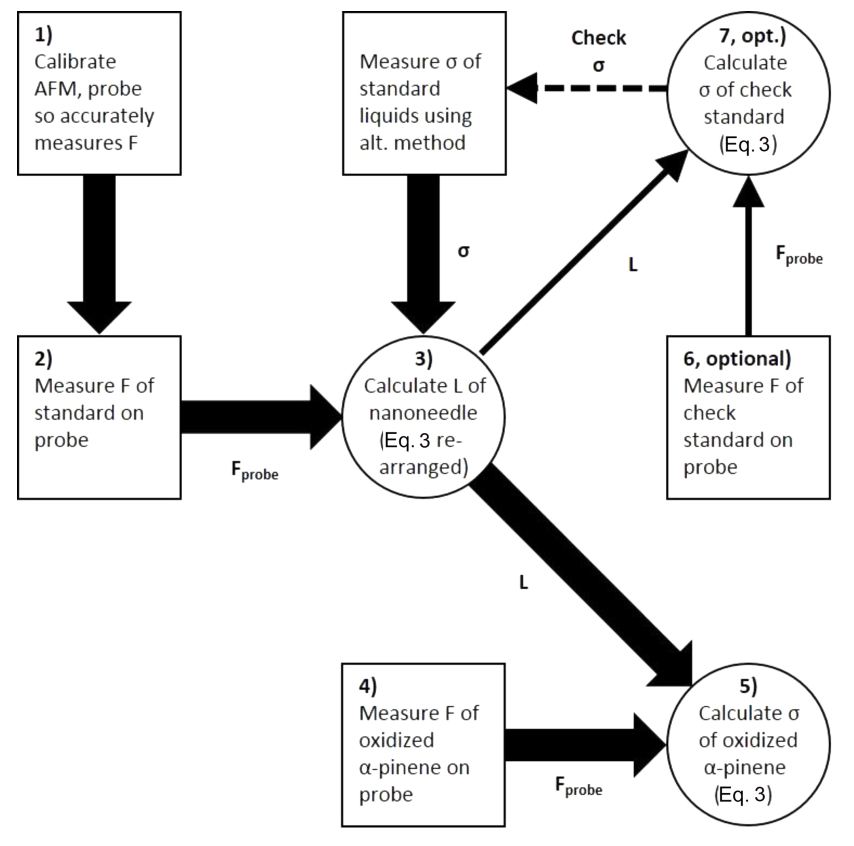

Figure 4. Procedure used to determine the surface tension of oxidized $\alpha$-pinene particles using the AFM. The cantilever's spring constant was determined (step 1), which allowed for the AFM to obtain force curves. Force curves of a liquid standard were obtained (step 2), and the nanoneedle's wetted perimeter was calculated with Eq. (3) given the standard's known surface tension (step 3). Force curves of the oxidized $\alpha$-pinene sample were obtained (step 4), and its surface tension was calculated with Eq. (3) given the nanoneedle's wetted perimeter (step 5). For initial tests, a check standard was used to verify the validity of the wetted perimeter and sample surface tension calculations (optional steps 6-7). 
Table 3 compares the mean surface tensions of oxidized $\alpha$ pinene particles measured in this study with published estimates for the surface tension of activating, oxidized $\alpha$-pinene particles (Engelhart et al., 2008; Huff Hartz et al., 2005; Prenni et al., 2007). Our results suggest that the surface tension of dry, oxidized $\alpha$-pinene particles is not very different from the surface tension of its VOC precursor. It is also apparent that the surface tension of oxidized $\alpha$-pinene particles formed in more humid conditions had a higher surface tension than oxidized $\alpha$-pinene particles formed in dry conditions.

These results appear to be in agreement with current theory. It is generally believed that the surface tension of an activating, oxidized $\alpha$-pinene particle is slightly lower than that of pure water, at $61.7 \mathrm{dyn}^{-1}$ (Engelhart et al., 2008). This is due to the depressive effect of organic surfactants in the droplets. The results from the particles generated at the higher of two humidities suggest that the surface tension is between the surface tension of pure water and the surface tension of the dry oxidized $\alpha$-pinene. This relationship is unlikely to be directly linear given that additive surface tensions only apply to chemicals with similar properties, which water and the organics produced from the oxidation of $\alpha$-pinene are not. Furthermore, the surface tension of the dry, oxidized $\alpha$ pinene particles was found to be similar to the surface tension of pure $\alpha$-pinene. This similarity in properties may be due to their similar structures. Now that a method suitable for the direct measurement of particle surface tension has been established, direct measurements of particles with several other moisture contents should be taken to examine the precise relationship between surface tension and moisture content in a particle. With modifications to the particle generation technique, this method can be used to experimentally measure the surface tension of activating particles.

\section{Conclusions}

A method was developed to measure the surface tension of collected liquid aerosol particles using atomic force microscopy. Particles are impacted on a clean surface until a film is formed, then probed with a clean tip in an atomic force microscope. This method minimizes processing of the particles and therefore reduces the risk of sample contamination. The method was verified and calibrated using standard liquids, whose surface tensions were in the range of the sample specimens. The standard liquid surface tensions were checked with a Wilhelmy plate. This method does not measure single particle surface tension but does dramatically reduce the required amount of material required to make bulk measurements.

Relatively dry, oxidized $\alpha$-pinene particles were found to have a surface tension similar to that of pure liquid $\alpha$-pinene. Oxidized $\alpha$-pinene particles with higher moisture content were found to have a surface tension significantly higher than that of pure $\alpha$-pinene, but lower than current assumptions for the surface tension of activating, oxidized $\alpha$-pinene particles. These preliminary results are consistent with the assumption of surface tension depression currently used to approximate the surface tension of activating aerosol particles. With modifications to the particle generation technique, this method can be used to experimentally measure the surface tension of particles closer to activation conditions.

\section{Data availability}

All the data pertinent to this paper are included in the tables.

Author contributions. D. Dutcher developed the technique described herein. A. Hritz performed the experiments with guidance from D. Dutcher and T. Raymond. A. Hritz prepared the initial manuscript with additional contributions from D. Dutcher and T. Raymond.

Acknowledgements. The authors thank NaugaNeedles and Mehdi Yazdanpanah for supplying the tips for the atomic force microscope and assisting in developing the methods described in this paper. The authors also thank James Maneval and Ray Dagastine for their assistance. The authors also appreciate the efforts of Rileigh Casebolt for imaging assistance.

Edited by: M. Ammann

Reviewed by: two anonymous referees

\section{References}

Asa-Awuku, A., Sullivan, A. P., Hennigan, C. J., Weber, R. J., and Nenes, A.: Investigation of molar volume and surfactant characteristics of water-soluble organic compounds in biomass burning aerosol, Atmos. Chem. Phys., 8, 799-812, doi:10.5194/acp8-799-2008, 2008.

Asa-Awuku, A., Nenes, A., Gao, S., Flagan, R. C., and Seinfeld, J. H.: Water-soluble SOA from Alkene ozonolysis: composition and droplet activation kinetics inferences from analysis of CCN activity, Atmos. Chem. Phys., 10, 1585-1597, doi:10.5194/acp10-1585-2010, 2010.

Boucher, O., Randall, D., Artaxo, P., Bretherton, C., Feingold, G., Forster, P., Kerminen, V., Kondo, Y., Liao, H., and Lohmann, U.: Clouds and aerosols, in: Climate change 2013: The physical science basis. Contribution of working group I to the fifth assessment report of the intergovernmental panel on climate change, Cambridge University Press, 571-657, 2013.

Conant, W. C., Nenes, A., and Seinfeld, J. H.: Black carbon radiative heating effects on cloud microphysics and implications for the aerosol indirect effect 1. Extended Köhler theory, J. Geophys Res.-Atmos., 107, 4604, doi:10.1029/2002JD002094, 2002.

Chumpitaz, L. D. A., Coutinho, L. F., and Meirelles, A. J. A.: Surface tension of fatty acids and triglycerides, J. Am. Oil Chem. Soc., 76.3, 379-382, 1999. 
Daisey, J. M. and Hopke, P. K.: Potential for ion-induced nucleation of volatile organic compounds by radon decay in indoor environments, Aerosol Sci. Tech., 19, 80-93, 1993.

Duplissy, J., Gysel, M., Alfarra, M., Dommen, J., Metzger, A., Prevot, A., Weingartner, E., Laaksonen, A., Raatikainen, T., and Good, N.: Cloud forming potential of secondary organic aerosol under near atmospheric conditions, Geophys. Res. Lett., 35, L03818, doi:10.1029/2007GL031075, 2008.

Engelhart, G. J., Asa-Awuku, A., Nenes, A., and Pandis, S. N.: CCN activity and droplet growth kinetics of fresh and aged monoterpene secondary organic aerosol, Atmos. Chem. Phys., 8, 39373949, doi:10.5194/acp-8-3937-2008, 2008.

Facchini, M. C., Mircea, M., Fuzzi, S., and Charlson, R. J.: Cloud albedo enhancement by surface-active organic solutes in growing droplets, Nature, 401, 257-259, 1999.

Facchini, M. C., Decesari, S., Mircea, M., Fuzzi, S., and Loglio, G.: Surface tension of atmospheric wet aerosol and cloud/fog droplets in relation to their organic carbon content and chemical composition, Atmos. Environ., 34, 4853-4857, 2000.

Hansen, A. M. K., Hong, J., Raatikainen, T., Kristensen, K., Ylisirniö, A., Virtanen, A., Petäjä, T., Glasius, M., and Prisle, N. L.: Hygroscopic properties and cloud condensation nuclei activation of limonene-derived organosulfates and their mixtures with ammonium sulfate, Atmos. Chem. Phys., 15, 14071-14089, doi:10.5194/acp-15-14071-2015, 2015.

Henning, S., Rosenørn, T., D’Anna, B., Gola, A. A., Svenningsson, B., and Bilde, M.: Cloud droplet activation and surface tension of mixtures of slightly soluble organics and inorganic salt, Atmos. Chem. Phys., 5, 575-582, doi:10.5194/acp-5-575-2005, 2005.

Huff Hartz, K. E., Rosenørn, T., Ferchak, S. R., Raymond, T. M., Bilde, M., Donahue, N. M., and Pandis, S. N.: Cloud condensation nuclei activation of monoterpene and sesquiterpene secondary organic aerosol, J. Geophys. Res.-Atmos., 110, D14208, doi:10.1029/2004JD005754, 2005.

Jang, M. and Kamens, R. M.: Newly characterized products and composition of secondary aerosols from the reaction of $\alpha$-pinene with ozone, Atmos. Environ., 33, 459-474, 1999.

Jonsson, A. M., Hallquist, M., and Saathoff, H.: Volatility of secondary organic aerosols from the ozone initiated oxidation of $\alpha$ pinene and limonene, J. Aerosol Sci., 38, 843-852, 2007.

King, S. M., Rosenoern, T., Shilling, J. E., Chen, Q., and Martin, S. T.: Increased cloud activation potential of secondary organic aerosol for atmospheric mass loadings, Atmos. Chem. Phys., 9, 2959-2971, doi:10.5194/acp-9-2959-2009, 2009.

Kiss, G., Tombácz, E., and Hansson, H.: Surface tension effects of humic-like substances in the aqueous extract of tropospheric fine aerosol, J. Atmos. Chem., 50, 279-294, 2005.

Köhler, H.: The nucleus in and the growth of hygroscopic droplets, T. Faraday Soc., 32, 1152-1161, 1936.

Laaksonen, A. and McGraw, R.: Thermodynamics, gas-liquid nucleation, and size-dependent surface tension, EPL (Europhysics Letters), 35, 367-372, 1996.

Moldanova, J. and Ljungström, E.: Modelling of particle formation from $\mathrm{NO}_{3}$ oxidation of selected monoterpenes, J. Aerosol Sci., 31, 1317-1333, 2000.

Moore, R., Ingall, E., Sorooshian, A., and Nenes, A.: Molar mass, surface tension, and droplet growth kinetics of marine organics from measurements of CCN activity, Geophys. Res. Lett., 35, L07801, doi:10.1029/2008GL033350, 2008.
Padday, J., Pitt, A., and Pashley, R.: Menisci at a free liquid surface: surface tension from the maximum pull on a rod, Journal of the Chemical Society, Faraday Transactions 1: Physical Chemistry in Condensed Phases, 71, 1919-1931, 1975.

Petters, M. D. and Kreidenweis, S. M.: A single parameter representation of hygroscopic growth and cloud condensation nucleus activity, Atmos. Chem. Phys., 7, 1961-1971, doi:10.5194/acp-71961-2007, 2007.

Petters, M. D., Wex, H., Carrico, C. M., Hallbauer, E., Massling, A., McMeeking, G. R., Poulain, L., Wu, Z., Kreidenweis, S. M., and Stratmann, F.: Towards closing the gap between hygroscopic growth and activation for secondary organic aerosol - Part 2: Theoretical approaches, Atmos. Chem. Phys., 9, 3999-4009, doi:10.5194/acp-9-3999-2009, 2009.

Praplan, A. P., Schobesberger, S., Bianchi, F., Rissanen, M. P., Ehn, M., Jokinen, T., Junninen, H., Adamov, A., Amorim, A., Dommen, J., Duplissy, J., Hakala, J., Hansel, A., Heinritzi, M., Kangasluoma, J., Kirkby, J., Krapf, M., Kürten, A., Lehtipalo, K., Riccobono, F., Rondo, L., Sarnela, N., Simon, M., Tomé, A., Tröstl, J., Winkler, P. M., Williamson, C., Ye, P., Curtius, J., Baltensperger, U., Donahue, N. M., Kulmala, M., and Worsnop, D. R.: Elemental composition and clustering behaviour of apinene oxidation products for different oxidation conditions, Atmos. Chem. Phys., 15, 4145-4159, doi:10.5194/acp-15-41452015, 2015.

Prenni, A. J., Petters, M. D., Kreidenweis, S. M., DeMott, P. J., and Ziemann, P. J.: Cloud droplet activation of secondary organic aerosol, J. Geophys. Res.-Atmos., 112, D10223, doi:10.1029/2006JD007963, 2007.

Prisle, N. L., Raatikainen, T., Laaksonen, A., and Bilde, M.: Surfactants in cloud droplet activation: mixed organic-inorganic particles, Atmos. Chem. Phys., 10, 5663-5683, doi:10.5194/acp-105663-2010, 2010.

Raymond, T. M. and Pandis, S. N.: Cloud activation of singlecomponent organic aerosol particles, J. Geophys. Res.-Atmos., 107, 4787, doi:10.1029/2002JD002159, 2002.

Schmelzer, J. W., Gutzow, I., and Schmelzer Jr., J.: Curvaturedependent surface tension and nucleation theory, J. Colloid Interf. Sci., 178, 657-665, 1996.

Schwier, A. N., Viglione, G. A., Li, Z., and Faye McNeill, V.: Modeling the surface tension of complex, reactive organicinorganic mixtures, Atmos. Chem. Phys., 13, 10721-10732, doi:10.5194/acp-13-10721-2013, 2013.

Serry, F.: Improving the accuracy of AFM force measurements: The thermal tune solution to the cantilever spring constant problem, Veeco Application Notes, 1-4, 2005.

Sorjamaa, R., Svenningsson, B., Raatikainen, T., Henning, S., Bilde, M., and Laaksonen, A.: The role of surfactants in Köhler theory reconsidered, Atmos. Chem. Phys., 4, 2107-2117, doi:10.5194/acp-4-2107-2004, 2004.

Tu, P., Hall, W. A., and Johnston, M. V.: Characterization of Highly Oxidized Molecules in Fresh and Aged Biogenic Secondary Organic Aerosol, Anal. Chem., 88, 4495-4501, doi:10.1021/acs.analchem.6b00378, 2016.

Uddin, M. H., Tan, S. Y., and Dagastine, R. R.: Novel characterization of microdrops and microbubbles in emulsions and foams using atomic force microscopy, Langmuir, 27, 2536-2544, 2011.

Wex, H., Petters, M. D., Carrico, C. M., Hallbauer, E., Massling, A., McMeeking, G. R., Poulain, L., Wu, Z., Kreidenweis, S. M., 
and Stratmann, F.: Towards closing the gap between hygroscopic growth and activation for secondary organic aerosol: Part $1-$ Evidence from measurements, Atmos. Chem. Phys., 9, 3987-3997, doi:10.5194/acp-9-3987-2009, 2009.

Yazdanpanah, M. M., Hosseini, M., Pabba, S., Berry, S. M., Dobrokhotov, V. V., Safir, A., Keynton, R. S., and Cohn, R. W.: Micro-wilhelmy and related liquid property measurements using constant-diameter nanoneedle-tipped atomic force microscope probes, Langmuir, 24, 13753-13764, 2008.
Yu, J., Cocker III, D. R., Griffin, R. J., Flagan, R. C., and Seinfeld, J. H.: Gas-phase ozone oxidation of monoterpenes: Gaseous and particulate products, J. Atmos. Chem., 34, 207-258, 1999.

Yum, K. and Yu, M.: Measurement of wetting properties of individual boron nitride nanotubes with the Wilhelmy method using a nanotube-based force sensor, Nano Lett., 6, 329-333, 2006. 